\title{
First report of Chikungunya fever in Rawalpindi, Pakistan
}

Lubna Meraj, ${ }^{1}$ Junaid Saleem, ${ }^{2}$ Shahzad Manzoor, ${ }^{1}$ Asfaa Ashfaq ${ }^{1}$ and Mohammad Khurram ${ }^{3}$

'Department of Medicine, District Headquarter Hospital Rawalpindi, Rawalpindi Medical University, Rawalpindi, Pakistan. ${ }^{2}$ Department of Medicine, Hearts International (Pvt) Hospital, affiliated with Islamic International Medical College, Rawalpindi, Pakistan (Correspondence to: J. Saleem: jslallar@ gmail.com). ${ }^{3}$ Department of Medicine, Benazir Bhutto Hospital, Rawalpindi Medical University, Rawalpindi, Pakistan

\begin{abstract}
Background: Chikungunya shares many clinical features with dengue fever, but to date, no case has been reported in Rawalpindi and surrounding areas.

Aims: To detect the presence in Rawalpindi of chikungunya masquerading as dengue fever.

Methods: An observational study was conducted at Rawalpindi Medical University from July to December 2017. Patients with clinical features suggestive of dengue fever, but negative for dengue virus NS1 antigen were included and tested at the National Institute of Health Islamabad, Pakistan, for chikungunya using reverse transcription polymerase chain reaction.

Results: We tested 129 patients and 28 were positive for chikungunya. There were $17(60.7 \%)$ men and 11 (39.3\%) women, with a mean age of 32.53 years (range 16-60 years). All had fever at presentation. Other clinical features at presentation were noted, such as fever, chills, fatigue, headache, myalgia, arthralgia, retro-orbital pain, abdominal pain, nausea, and diarrhoea. No long-term sequelae or bleeding diatheses were seen and there was no mortality reported.

Conclusions: The clinical features observed and investigated confirmed our reporting of the first case of chikungunya in Rawalpindi, Pakistan.

Keywords: chikungunya, clinical features, dengue fever, Rawalpindi, reverse transcription polymerase chain reaction

Citation: Meraj L; Saleem J; Manzoor S; Ashfaq A; Khurram M. First report of Chikungunya fever in Rawalpindi, Pakistan. East Mediterr Health J. 2020;26(6):744-747. https://doi.org/10.26719/emhj.19.095

Received: 04/09/18; accepted:14/02/19

Copyright (C) World Health Organization (WHO) 2020. Open Access. Some rights reserved. This work is available under the CC BY-NC-SA 3.0 IGO license (https://creativecommons.org/licenses/by-nc-sa/3.o/igo).
\end{abstract}

\section{Introduction}

Chikungunya is a viral illness caused by the positive-sense single-stranded RNA chikungunya virus (CHIKV), belonging to the genus Alphavirus, and family Togaviridae. It is transmitted by the bite of infected Aedes aegypti and Aedes albopictus mosquitoes. The disease was first documented in 1952 as an outbreak in Makonde Plateau, on the border of Mozambique and Tanzania. The word chikungunya has been taken from Mokonde language, and means the "contorted or bent appearance" that occurs in affected patients. Since then, many outbreaks have been noted in 60 countries on four continents, namely Asia, Africa, South America and Europe (1). In Pakistan, chikungunya was first documented in 4 rodent and 1 human sample in 1983 (2). The first recorded human case in Pakistan was reported in 2011 in Lahore (3). Outbreaks have been described in India and Karachi, Pakistan in the last two years $(2016-2017)(4,5)$.

Chikungunya has not been described previously in Rawalpindi, Pakistan. We have been dealing with dengue epidemics for the last few years (6). With knowledge of recent outbreaks of Chikungunya in India (4) and Karachi (5) and a high index of suspicion, we planned this study to detect the presence of CHIKV and its clinical features in Rawalpindi.

\section{Methods}

This cross-sectional observational study was conducted at the Department of Medicine, District Headquarter
Hospital, Rawalpindi Medical University. Due to a Government initiative against dengue fever, all patients presenting with acute onset of fever (duration 2-10 days) and suspected to have dengue fever were admitted to the hospital. Patients who were negative for dengue markers (NS1, IgG and IgM) from 1 July to 31 December 2017 were evaluated for possible CHIKV infection.

The study was approved by the Ethical Committee of the District Headquarter Hospital, and consent was obtained from all patients before sampling. A detailed history was recorded, and clinical examination was performed, including, blood cultures, and thick and thin blood smear testing for malarial parasites and hepatitis. Patients with clinical features of urinary tract infection, pneumonia, throat infection, and acute gastroenteritiswere excluded. Patients with conditions associated with cytopenia on complete blood counts, such as liver disease, haematological disease, and autoimmune disorders, as well as patients receiving immunomodulatory medication were also excluded.

Blood samples $(2 \mathrm{ml}$ ) from the antecubital fossa collected into vacuum containers were were sent to the National Institute of Health (NIH) Islamabad, Pakistan, our local reference laboratory, for detection of CHIKV. Virus was detected by polymerase chain reaction (PCR) using US-CDC Trioplex Real-Time RT-PCR kit (US Centers for Disease Control and Prevention, Atlanta, GA, USA), which is the diagnostic kit recommended by 
the World Health Organization (WHO). Patients who were positive for chikungunya by PCR were included in this study. All patients were treated conservatively with antipyretics and analgesics, and where needed, intravenous infusions. Patients who were asymptomatic at discharge were not called back for follow-up. Those who had persistent symptoms were followed up in the outpatient department, but none had persistent arthralgia or any other symptom after 2 weeks.

Age, sex, occupation, address, clinical features, duration of illness, main symptoms, findings on clinical examination, and complete blood counts of the included patients were noted on a specifically designed form, with personal details, symptoms present at the time of admission, and laboratory test results on days $1-3$. The $\chi^{2}$ test was used for statistical analysis.

\section{Results}

A total of 129 patients were tested for chikungunya and $28(21.7 \%)$ were positive. Seventeen $(60.7 \%)$ of them were male and $11(39.3 \%)$ female, with a mean age of 32.53 years (range 16-6o years). Nineteen (67.8\%) patients were from Rawalpindi, 1 (3.57\%) was from Islamabad, and the remaining 8 (28.5\%) were from towns around Rawalpindi/ Islamabad twin city complex. There were no cases presently living in rural areas (although some had a history of migrating from rural areas), and only 1 (3.57\%) gave a history of travel to a rural area in the recent past.

All 28 patients had fever at presentation ranging from 37.7 to $38.9^{\circ} \mathrm{C}$. The duration of fever was $2-8$ days in 25 $(89.28 \%)$ cases. Two $(7.14 \%)$ patients had fever of $<2$ days duration and 1 (3.57\%) had a history of 16 days of fever. Seven $(25.0 \%)$ patients experienced chills before fever. Mean duration of fever was 5.04 days (range 0-16 days). Fatigue was reported by 27 patients $(96.4 \%)$, and headache by $22(78.6 \%)$. Nineteen patients had myalgia $(67.6 \%)$, and $16(57.1 \%)$ complained of arthralgia. Other clinical features were: retro-orbital pain ( $n=11 ; 39.2 \%)$, chills $(n=7 ; 25.0 \%)$, abdominal pain at presentation $(n=7)$, rash on the body $(n=4 ; 14.3 \%)$, nausea $(n=3 ; 10.7 \%)$, cough $(n=2 ; 7.14 \%)$ and diarrhea $(n=2)$.

Physical examination revealed average systolic blood pressure (BP) of 102.14 (range 90-150) $\mathrm{mmHg}$ and a diastolic BP of 66.25 (range $50-80$ ) $\mathrm{mmHg}$. Five $(17.8 \%$ ) patients had BP of $90 / 60 \mathrm{mmHg}$ and 1 (3.57\%) had BP of 90/50 $\mathrm{mmHg}$. The average pulse rate was 87.71 (range $76-102$ ) beats/min. Out of the 15 cases with temperature above $37.8^{\circ} \mathrm{C}$ (range $37.8-38.9^{\circ} \mathrm{C}$ ), 4 had a pulse rate of $\geq 100$ beats/min, 6 had a pulse rate between 90 and 99 beats/min, and 5 had relative bradycardia with a pulse rate of $\leq 89$ beats/min.

Laboratory reports were available for days 1-3 after admission to the hospital (Table 1). There was a tendency toward pancytopenia. Haematocrit was < 40 in 14 of 26 (53.8\%) patients on day 1 , in 13 of $22(59.0 \%)$ on day 2 and in 12 of $18(66.6 \%)$ on day 3 . Total leukocyte count on day 1 was $<4 \times 109 / \mathrm{L}$ in $8 / 26(30.7 \%)$ patients, and $>11 \times 109 / \mathrm{L}$ in 2 patients $(7.6 \%)$. On day 2,7 of $22(31.8 \%)$ had leukopenia,
Table 1 Laboratory results in patients positive for chikungunya virus

\begin{tabular}{lccc} 
Test & Day 1 & Day 2 & Day 3 \\
& (26 patients) & (22 patients) & (18 patients) \\
\hline Haematocrit, \% & 37.89 & 37.56 & 37.33 \\
& $(23.0-47.8)$ & $(27.5-44.9)$ & $(24.6-48.8)$ \\
Total leukocyte count & 6.69 & 3.96 & 3.99 \\
$\left(\times 10^{9} / 1\right)$ & $(1.8-47.0)$ & $(1.3-7.7)$ & $(1.9-7.5)$ \\
Platelet counts & 105.4 & 124.8 & 140.1 \\
$\left(\times 10^{9} / 1\right)$ & $(19.0-231.0)$ & $(30.0-333.0)$ & $(38.0-273.0)$ \\
\hline Results measured on 3 consecutive days; presented as average (range).
\end{tabular}

and on day 3,10 of $22(44.4 \%)$. No leukocytosis was noted on days 2 and 3. Platelet count showed a steady rise over the 3 -day observation period. On day 1, 18/26 (59.2\%) patients had thrombocytopenia (platelet count < $150 \times 109 / \mathrm{L})$, and $3(11.5 \%)$ had severe thrombocytopenia (platelet count $<50 \times 109 / \mathrm{L}$ ). On day 2 the corresponding figures were $13 / 22(59.0 \%)$ and $2 / 22(9.09 \%)$, and for day 3 they were $10 / 18(55.5 \%)$ and $2 / 18$ (11.1\%).

\section{Discussion}

Chikungunya is a viral illness that is spread by the bite of infected A. aegypti or A. albopictus mosquitoes. It is rarely a fatal condition and due to its nonspecific symptoms and nonlethal nature, it is underdiagnosed in the community even in areas where it is endemic (6). Presentation is mainly with high-grade fever and severe arthralgia, and it may be difficult to differentiate it on clinical grounds alone from dengue fever, Rift Valley fever or malaria in endemic areas. There may be other associated symptoms such as myalgia, nausea, headache, fatigue and rash. Treatment in most cases is symptomatic. Hospitalization may be needed for severe disease. Symptoms usually resolve within a week but arthralgia is reported to last for several months in up to $4 \%$ of patients (7).

Even though Pakistan is located in the endemic area for chikungunya, it was not until 2011 that the first recorded human case was reported during a dengue outbreak in Lahore (3). We do not know how many undiagnosed cases occurred, but the current documented outbreak started in week 2 of November 2016 and continued until March 2017 (5), although the number of cases reported was erroneously high $(4,8)$. This outbreak was mainly localized in Karachi, Southern Pakistan. Outbreaks of chikungunya have already been reported in India in the past 2 years (9). There is an increasing trend in the incidence of mosquito-borne illnesses in Pakistan, which is attributed to climate change. The winters are getting milder and shorter while the summers are getting harsher and longer, leading to an increase in breeding span for the disease vectors $(7,10)$.

No case of chikungunya has been reported in Rawalpindi to date. We decided to look for CHIKV infection in Rawalpindi, enrolling all suspected cases of fever that were negative for dengue serology. We found 28 cases that were positive for CHIKV infection, confirmed by NIH using WHO-recommended kits. As the viraemia 
is usually short lived and we only performed PCR, and did not check for IgM antibodies, we may have missed a few cases, which was a possible limitation to this study.

We found differences in the clinical features of the disease between our patients and those from a previous study in Karachi (7) (Table 2). Our patients had a lower incidence of high fever $\left(38.9^{\circ} \mathrm{C}\right)$, arthralgia and rash, and none had arthritis/joint swelling, compared with patients in Karachi. The incidence of headache, myalgia and thrombocytopenia was nearly the same. In addition to the above, we found a high incidence of fatigue at presentation (96.4\%), as well as retro-orbital pain (39.2\%), unexplained abdominal pain $(25.0 \%)$, chills $(25.0 \%)$, nausea (10.7\%), cough (7.14\%) and diarrhoea (7.14\%). These are not among the listed classical features of the disease (11) and may have been coincidental findings.

\section{Conclusion}

Chikungunya may be the cause of many undiagnosed acute febrile illnesses that may clinically resemble dengue fever. For the past 2 years many cases have been described in Karachi and Hyderabad, and the infection seems to be rapidly travelling up from the south. This is the first time that chikungunya has been reported in
Table 2 Comparative incidence of clinical features in present study and previous study from Karachi (7)

\begin{tabular}{lcc} 
Clinical feature & Present study & Karachi study \\
Fever $\left(>38.9^{\circ} \mathrm{C}\right)$ & 10.7 & 85.9 \\
Rash & 14.3 & 29.1 \\
Arthritis/joint swelling & 0 & 78.9 \\
Arthralgia & 57.1 & 88.4 \\
Headache & 78.6 & 72.4 \\
Myalgia & 67.6 & 69.3 \\
Thrombocytopenia & 59.2 & 69.3 \\
\hline
\end{tabular}

Results presented as percentages.

Rawalpindi. Presently, the diagnostic tools are available at NIH Islamabad only. We need to keep a high index of suspicion for detecting and reporting these cases and developing diagnostic ability at local levels. We also noted some differences in the clinical features of the disease from the south of the country; mainly a lower incidence of high fever and joint swelling, and a higher incidence of fatigue at presentation.

Funding: None.

Competing interests: None declared.

\section{Première notification d'un cas de fièvre à virus Chikungunya à Rawalpindi (Pakistan) Résumé}

Contexte : La fièvre à virus Chikungunya partage de nombreuses caractéristiques cliniques avec la dengue, mais à ce jour, aucun cas n'a été notifié à Rawalpindi ni dans les zones alentours.

Objectifs : La présente étude visait à détecter la présence de fièvre à virus Chikungunya à Rawalpindi confondue avec la dengue.

Méthodes : Une étude d'observation a été menée à l'Université médicale de Rawalpindi entre juillet et décembre 2017. Les patients présentant un tableau clinique évocateur de dengue, mais dont les résultats du dépistage de l'antigène NS1 du virus de la dengue étaient négatifs, ont été inclus et ont fait l'objet d'un dépistage du Chikungunya à l'Institut national de la santé d'Islamabad (Pakistan) selon la méthode de transcription inverse suivie d'une réaction d'amplification génique.

Résultats: Nous avons effectué un dépistage du Chikungunya auprès de 129 patients. Parmi eux, 28 ont été testés positifs. Il s'agissait de $17(60,7 \%)$ hommes et 11 (39,3\%) femmes, pour un âge moyen de 32,53 ans (fourchette comprise entre 16 et 60 ans). Tous avaient de la fièvre lorsqu'ils s'étaient présentés. D'autres signes cliniques à l'arrivée des patients ont été relevés : frissons, fatigue, céphalées, douleurs musculaires, douleurs articulaires, douleurs rétro-orbitaires, douleurs abdominales, nausées et diarrhée. Aucune séquelle à long terme ou diathèse hémorragique n'a été observée et aucun décès n'a été signalé.

Conclusions : Les caractéristiques cliniques observées et examinées ont permis de confirmer qu'il s'agissait donc de la notification du premier cas confirmé de fièvre à virus Chikungunya à Rawalpindi (Pakistan).

$$
\begin{aligned}
& \text { التقرير الأول حول حمّى الشيكونجونيا في راو البيندي، باكستان }
\end{aligned}
$$

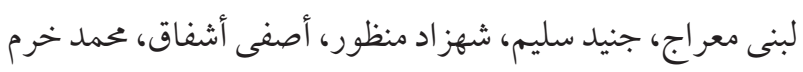

الخلفية: يشترك داء الشيكونجونيا في العديد من السمات السريرية مع حمى الضنك، غير أنه لم يُبلغ حتى يومنا هذا بوجود أي حالة في راوالبيندي والمناطق المجاورة هلا.

الأهداف: هدفت هذه الدراسة إلى الكشف عن وجود داء الشيكونجونيا متخفياً في صورة حمى الضنك في راو البيندي. 


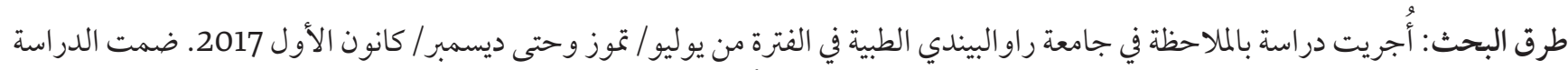

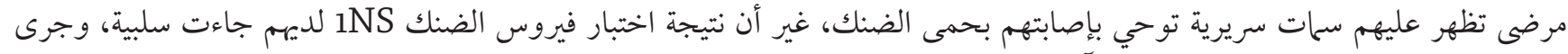

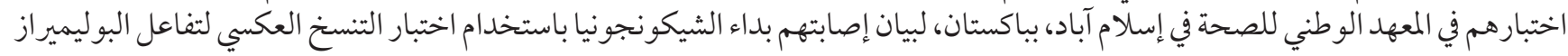
المتسلسل.

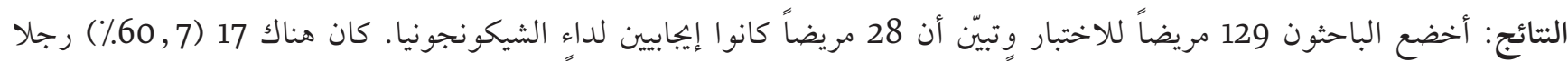

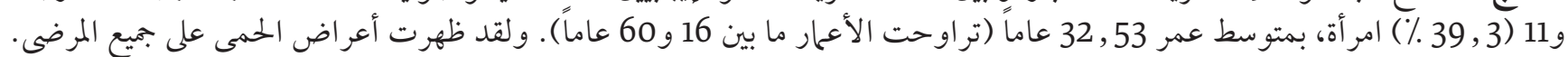

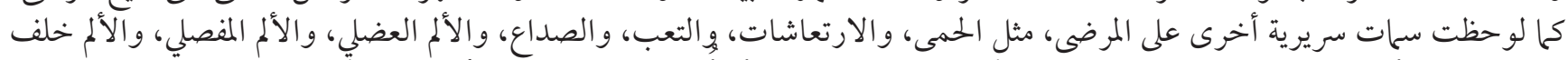

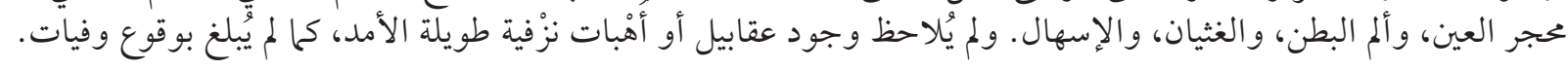

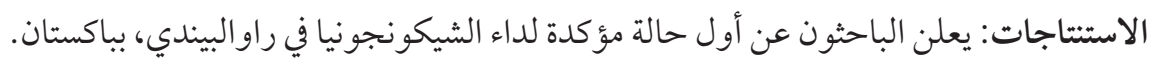

\section{References}

1. Chikungunya, 12 April 2017 [website]. World Health Organization; 2019 (http://www.who.int/mediacentre/factsheets/fs327/en/, accessed 3 December 2019).

2. Darwish MA, Hoogstraal H, Roberts TJ, Ahmed IP, Omar F A. A sero-epidemiological survey for certain arboviruses (Togaviridae) in Pakistan. Trans R Soc Trop Med Hyg. 1983;77(4):442-5. http://dx.doi.org/10.1016/0035-9203(83)90106-2 PMID:6314612

3. Afzal MF, Naqvi SQ, Sultan MA, Hanif A. Chikungunya fever among children presenting with nonspecific febrile illness during an epidemic of dengue fever in Lahore, Pakistan. Merit Res J Med Med Sci. 2015 Mar;3(3):69-73. http://www.meritresearchjournals.org/mms/index.htm

4. Mallhi TH, Khan YH, Khan AH, Tanveer N, Qadir MI. First chikungunya outbreak in Pakistan: a trail of viral attacks. New Microbes New Infect. 2017 Jun 1;19:13-14. http://dx.doi.org/10.1016/j.nmni.2017.05.008 PMID:28663798

5. $\quad$ Rauf M, Zahra F, Manzoor S, Mehmood A, Bhatti S. Outbreak of chikungunya in Pakistan. Lancet Infect Dis. 2017 Mar;17(3):258. https://doi.org/10.1016/S1473-3099(17)30074-9

6. Naqvi S, Bashir S, Rupareliya C, Shams A, Giyanwani PR, Ali Z. Clinical spectrum of chikungunya in Pakistan. Cureus. 2017 Jul 6;9(7):e1430. http://dx.doi.org/10.7759/cureus.1430 PMID:28924518

7. Lo Presti A, Cella E, Angeletti S, Ciccozzi M. Molecular epidemiology, evolution and phylogeny of Chikungunya virus: an updating review. Infect Genet Evol. 2016 Jul;41:270-8. http://dx.doi.org/10.1016/j.meegid.2016.04.006 PMID:27085290

8. Aamir UB, Badar N, Salman M, Ahmed M, Alam MM. Outbreaks of chikungunya in Pakistan. Lancet Infect Dis. 2017 May;17(5):483. http://dx.doi.org/10.1016/S1473-3099(17)30191-3 PMID:28447956

9. Wasif S. Chikungunya outbreak traced back to India. The Express Tribune, Pakistan. 26 December 2016 (http://tribune.com.pk/ story/1274991/no-preventive-measures-chikungunya-outbreak-traced-back-india/, accessed 3 December 2019).

10. Rehman, S. Rising trend of vector-borne diseases in Pakistan reported: WHO. Business Recorder. 25 April 2014 (https://www. brecorder.com/2014/04/25/169191/rising-trend-of-vector-borne-diseases-in-pakistan-reported-who/, accessed 3 December 2019).

11. Weaver SC, Lecuit M. Chikungunya virus and the global spread of a mosquito-borne disease. N Engl J Med. 2015 Mar 26;372(13):1231-9. http://dx.doi.org/10.1056/NEJMra1406035 PMID:25806915 